\title{
Feasibility of using fallen tea leaves as litter in broiler rearing
}

\author{
S Chakma ${ }^{1}$, MY Miah ${ }^{1} *$, A Ara ${ }^{1}$, MH Kawsar ${ }^{2}$ \\ ${ }^{1}$ Department of Dairy and Poultry Science, Sylhet Agricultural University, Sylhet 3100, \\ Bangladesh; ${ }^{2}$ Department of Dairy and Poultry Science, Patuakhali Science and Technology University, \\ Patuakhali, Bangladesh
}

\begin{abstract}
One hundred eighty straight run day old Cobb-500 broilers were reared on rice husk, sawdust, wood shaving and chopped tea leaves litter up to 35 days of age. The broilers were fed ad libitum. At 35 days the body weight of chicken reared on sawdust attained the highest body weight $(p<0.01)$ than other litters. FCR was the best on saw dust. The moisture content of different litters did not differ significantly. Oocyst population in rice husk was found to be higher $(p<0.01)$ than those on other litters, except those reared on wood shaving. Moisture content of litters and oocyst population were positively correlated at 14 and 35 days and negatively correlated at 21 and 28 days of age. The litter cost per broiler and per kg broiler was the highest on rice husk (RH), intermediate on sawdust (SD), Wood shavings (WS) and the lowest on chopped fallen tea leaves (CFTL). It was concluded that it may be possible to minimize the cost of litter by using CFTL.
\end{abstract}

Key words: Broiler, litter, tea leaves, litter cost, oocyst.

Bangladesh Animal Husbandry Association. All rights reserved.

Bang. J. Anim. Sci. 2012. 41 (1): 52-54

\section{Introduction}

For successful broiler production, litter plays a vital role. Litter absorb moisture of droppings, keep floor dry and provide insulation under foot and give birds a suitable medium on which feeding, watering and other management are performed. The requisites of good litters are availability, price, moisture absorption, particle size, cleanliness, smoothness and free from moulds and comfort ability. Usual litter materials used worldwide are chopped rice straw, rice husk $(\mathrm{RH})$, sawdust(SD), sugarcane pulp, oat hulls, corncobs, grinded corncobs, paper mill byproducts, wood shaving, sand, ash, peat moss, keshari hulls and peanut hulls (Ghany et al. (1977), Jull (1979), Ranade and Rajmane (1990).

In Bangladesh, $\mathrm{RH}$ and sawdust (SD) are the most commonly used litter for rearing broilers. There are some cheaper unconventional litters; wheat straw, chopped straw, sand and paper mill by products. Substitution of conventional litter by cheaper unconventional one must be based on research evidences. In tea producing areas of Bangladesh, huge fallen tea leaves are available. The effects of using chopped fallen tea leaves (CFTL) as a litter material for broilers have not yet been assessed. The present study was undertaken to evaluate the effect of CFTL on the performance and economic feasibility of using tea leaves as a litter material in rearing broilers.

\section{Materials and methods}

A total of 180 day old Cobb 500 straight run broilers were randomly distributed to 4 litter treatments; RH, SD, WS and CFTL at a depth of 5 $\mathrm{cm}$ having 3 replications each. The CFTL were collected from the tea garden and dried on the sun. The CFTL were chopped by chopping machine and used as litter material. The broilers were fed ad libitum on 2 standard diets; broiler starter (0-21 days), broiler grower and broiler finisher (28 - 35 days) diets. The broilers were exposed to a continuous lighting of 23 hours and dark period of 1 hour during 24 hour of the day. Each broiler was given a floor space of $1000 \mathrm{~cm}^{2}$. Brooding temperature started at $34^{\circ} \mathrm{C}$ and reduced @ $2.5^{\circ} \mathrm{C}$ per week until $21^{\circ} \mathrm{C}$.

Representative litter samples were collected from 4 corners and central position of each pen weekly and mixed thoroughly for making composite samples. Half of the mixed samples were used for the determination of moisture content and the remaining half was processed to determine coccidial oocyst population. The coccidial oocysts were determined every week. Moisture content of every representative sample was determined in duplicate at $105^{\circ} \mathrm{C}$ until constant weight was recorded. The samples were stored in a refrigerator before examination. The number of oocyst per gram of litter was counted by following the method reported by Karim et al. (1994) with slight modification. $10 \mathrm{~g}$ litter samples were 
soaked in $100 \mathrm{ml}$ of water for 24 hours. It was mixed thoroughly by vigorous shaking in a screwcapped bottle and subsequently sieved through a tea strainer to remove the coarse particles. After centrifugation (at 1100 RPM for 5 minutes) the supernatant was discarded and the sediment was resuspended in $100 \mathrm{ml}$ of saturated salt solution. Two chambers of a Mc Master counting slide were filled with the suspension with the help of a pipette and allowed 3 to 5 minutes for floatation. The number of oocyst was counted by a tally counter using a $6 x$ eyepiece and $10 x$ objectives of a compound microscope. The body weight (initial and weekly), feed consumption and mortality were recorded. Body weight gain and feed conversion ratio were calculated for each replication. Temperature, humidity and moisture contents and the Oocyst population were counted per replication.

The collected and calculated data were subjected to analysis of variance in a Completely Randomized Design using SAS computer packaged program. Significant differences were identified by Duncan's Multiple Range Test.

\section{Results and discussion}

The highest body weight $(p<0.01)$ of broilers (Table 1 ) attained on SD litter in comparison with other litters at all ages the results are with the observation of Hussain et al. (1996). They did not find any differences of body weight among different litter materials. It was revealed that 14 and 21 days feed consumption was almost similar on all litters, while differ significantly at 28 to 35 days among the litters.
It is evident that (Table 1 ) feed conversion ratio (FCR) was the poorest on WS, while RH and CFTL comparable FCR. The results are not consistent with the observation of Hussain et al. (1996) who did not find any difference in FCR of broilers which reared on SD, dried common grass (CG) and $1: 1$ mixture of SD and CG.

The litter cost per broiler and per $\mathrm{kg}$ broiler (Table 2) was the highest on $\mathrm{RH}$, intermediate on SD, WS and the lowest on CFTL. No bird was died on any litter. The results agree with the findings of Haque and Chowdhury (1994) and Podder (1996).

The initial moisture contents of fresh $\mathrm{RH}, \mathrm{WS}, \mathrm{SD}$ and CFTL were 10.39, 14.4610 .64 and $13.48 \%$ respectively. At the end of the experiment, respective moisture contents were increased $(p<0.05)$ to $20.35,20.47,19.42$ and $21.76 \%$ (Table 3). Differences of moisture from initial to final were $9.96 \%, 6.01 \%, 8.78 \%$ and $10.28 \%$ respectively. The study revealed that CFTL appeared to have the highest moisture absorbing capability followed by RH, SD and WS $(p<0.05)$.

No visual evidence of either leg abnormalities or breast blister in any bird was observed in any litter. The results agree with the findings of Haque and Chowdhury (1994) and Podder, (1996). They did not find any abnormalities on $\mathrm{RH}$ and SD.

Oocyst population detected in all samples collected at $14^{\text {th }}$ day was small (Table 4 ). It was gradually increased and reached to a peak at $28^{\text {th }}$ day and then declined in all litters (Table 4.). At $28^{\text {th }}$ day, RH contained higher $(p<0.01)$ oocyst than that of other litters.

Table 1. Effect of Rice husk (RH), Wood shaving (WS), Saw dust (SD) and Chopped Fallen Tea Leaves (CFTL) litters on the performance of broiler at different ages

\begin{tabular}{|c|c|c|c|c|c|c|}
\hline \multirow{2}{*}{ Variable } & \multirow{2}{*}{ Age(day) } & \multicolumn{4}{|c|}{ Litter } & \multirow{2}{*}{ Significance } \\
\hline & & $\mathrm{RH}$ & WS & SD & CFTL & \\
\hline \multirow{5}{*}{$\begin{array}{l}\text { Live weight } \\
\text { (g/broiler) }\end{array}$} & 7 & 166.22 & 165.67 & 167.56 & 164.22 & NS \\
\hline & 14 & 437.23 & 423.34 & 423.67 & 423.89 & NS \\
\hline & 21 & $807.78^{a}$ & $775.56^{\mathrm{bc}}$ & $810.00^{a}$ & $784.89^{b}$ & $* *$ \\
\hline & 28 & $1234.45^{b}$ & $1144.11^{d}$ & $1266.89^{a}$ & $1198.98^{c}$ & $* *$ \\
\hline & 35 & $1717.26^{\mathrm{b}}$ & $1563.89^{d}$ & $1745.01^{a}$ & $1634.49^{c}$ & $* *$ \\
\hline \multirow{4}{*}{$\begin{array}{l}\text { Feed intake } \\
\text { (g/broiler) }\end{array}$} & 14 & $705.73^{a}$ & 692.62 & $660.62^{b}$ & $693.18^{a b}$ & $*$ \\
\hline & 21 & 1278.42 & 1278.42 & 1269.71 & 1287.51 & NS \\
\hline & 28 & $2031.40^{\mathrm{ab}}$ & $2052.40^{\mathrm{ab}}$ & $1932.49^{c}$ & $1983.51^{b}$ & $* *$ \\
\hline & 35 & $2741.80^{\mathrm{ab}}$ & $2640.18^{\mathrm{ab}}$ & $2648.29^{\mathrm{ab}}$ & $2626.62^{b}$ & $* *$ \\
\hline \multirow{4}{*}{$\begin{array}{l}\text { Feed } \\
\text { conversion } \\
\text { ratio }\end{array}$} & 14 & $1.62^{b}$ & $1.64^{\mathrm{a}}$ & $1.56^{c}$ & $1.64^{\mathrm{a}}$ & $*$ \\
\hline & 21 & $1.59^{b}$ & $1.67^{a}$ & $1.57^{\mathrm{b}}$ & $1.64^{\mathrm{a}}$ & $* *$ \\
\hline & 28 & $1.65^{b}$ & $1.79^{\mathrm{a}}$ & $1.53^{c}$ & $1.66^{\mathrm{b}}$ & $* *$ \\
\hline & 35 & $1.60^{\mathrm{b}}$ & $1.69^{a}$ & $1.52^{c}$ & $1.61^{b}$ & $* *$ \\
\hline
\end{tabular}

Values with different superscript(s) in same row differed significantly; NS, non-significant; $*, \mathrm{p}<0.05 ; * *$, $\mathrm{p}<0.01$ 
Table 2. Cost of different litters on broiler production

\begin{tabular}{llll}
\hline Litter & $\begin{array}{l}\text { Cost/kg } \\
\text { fresh litter } \\
(\mathrm{Tk})\end{array}$ & $\begin{array}{l}\text { Litter Cost/ } \\
\text { broiler (Tk) }\end{array}$ & $\begin{array}{l}\text { Litter Cost/ } \\
\text { kg weight } \\
\text { gain (Tk) }\end{array}$ \\
\hline RH & 5.15 & 5.50 & 3.21 \\
WS & 4.85 & 1.46 & 0.94 \\
SD & 1.30 & 1.45 & 0.84 \\
CFTL & 2.5 & 1.1 & 0.67 \\
\hline
\end{tabular}

Table 3. Moisture contents of different litters at the initial and of $35^{\text {th }}$ day

\begin{tabular}{lllll}
\hline $\begin{array}{l}\text { Age } \\
\text { (day) }\end{array}$ & $\begin{array}{l}\text { Rice } \\
\text { husk }\end{array}$ & $\begin{array}{l}\text { Wood } \\
\text { shaving }\end{array}$ & $\begin{array}{l}\text { Saw } \\
\text { dust }\end{array}$ & $\begin{array}{l}\text { Tea } \\
\text { leaves }\end{array}$ \\
\hline Initial & $10.39^{\mathrm{c}}$ & $14.46^{\mathrm{a}}$ & $10.64^{\mathrm{c}}$ & $13.78^{\mathrm{b}}$ \\
35 & $20.35^{\mathrm{b}}$ & $20.47^{\mathrm{b}}$ & $19.42^{\mathrm{c}}$ & $21.36^{\mathrm{a}}$ \\
\hline
\end{tabular}

Values in same row bearing different superscripts differed significantly $(p<0.05)$

Table 4. Coccidial oocyst population $\times 10^{3}$ in different treatment groups

\begin{tabular}{lllll}
\hline $\begin{array}{l}\text { Age } \\
\text { (day) }\end{array}$ & $\begin{array}{llll}\text { Rice } \\
\text { husk }\end{array}$ & $\begin{array}{l}\text { Wood } \\
\text { shaving }\end{array}$ & $\begin{array}{l}\text { Saw } \\
\text { dust }\end{array}$ & $\begin{array}{l}\text { Tea } \\
\text { leaves }\end{array}$ \\
\hline 14 & 1.82 & 1.39 & 1.02 & 1.66 \\
21 & 1.82 & 1.95 & 1.16 & 1.70 \\
28 & $2.00^{\mathrm{a}}$ & $1.95^{\mathrm{b}}$ & $1.33^{\mathrm{d}}$ & $1.74^{\mathrm{c}}$ \\
35 & 1.82 & 1.52 & 1.14 & 1.71 \\
\hline
\end{tabular}

Values in same row bearing different superscripts differed significantly $(p<0.01)$

Table 5. Correlation between moisture content and coccidial oocyst population at different rearing periods

\begin{tabular}{lcc}
\hline Age (day) & r-value & Significance level \\
\hline 14 & +0.012 & NS \\
21 & -0.541 & $*$ \\
28 & -0.710 & $* *$ \\
35 & +0.073 & NS \\
\hline
\end{tabular}

NS, non-significant; $*, \mathrm{p}<0.05 ; * *, \mathrm{p}<0.01$

The correlations of moisture with coccidosis are shown in Table 5 . The number of oocysts increased with the increase of moisture in litter at $14^{\text {th }}$ and $35^{\text {th }}$ day, but at 21 and $28^{\text {th }}$ day, the number of oocysts had a tendency of negative relations with litter moisture. These pattern of positive and negative correlations of moisture with the number of oocysts $(P>0.05)$ signify that the number of oocysts population in litter may not follow in definite age related response. Correlations between moisture and oocyst population did not differ significantly among the treatment groups $(\mathrm{P}>0.05)$.

It can be concluded from the study that different types of litter materials had no effect on moisture content and survivability, but body weight on sawdust was significantly higher than other treatment groups. Tea leaves absorbed higher amount of moisture $(21.36 \%)$ in comparison with others litter materials at 35 days of age. Broilers were not be affected by breast blister or leg abnormalities if reared on rice husk, sawdust, wood shaving and tea leaves litter. Oocyst population was increased in birds reared on rice husk while the cost of tea leaves was the lowest.

\section{References}

Ghany K, Kossar K and Machalie E (1977). The effects of different types of litter on body weights, feed efficiency and viability of chicks, Poultry Abstracts, 3: 57-58.

Haque MI and Chowdhury SD (1994). Use of rice husk litter at different depths for broiler chicks during summer. British Poultry Science, 35: 809-812.

Hussain SA, Zahid S and K (1996). Effect of different types of litter materials on the performance of broilers. Pakistan Journal of Zoology, 28: 181-182.

Jull MA (1979). Kinds of litter. Poultry Husbandry. Tata McGrow Hill Publishing Company Limited. New Delhi- 110020.

Karim MJ, Begum N and Khan MSR (1994). Prevalence of coccidiosis in broiler on two farms in Bangladesh. Pakistan Journal of Scientific and Industrial Research, 37: 339341.

Podder CK (1996). Performance of broiler chicks reared on sawdust litter at different depths. Master of Science in Poultry Science, Thesis, Dept. of Poultry Science, Bang. Agril. Univ., Mymensingh.

Ranade AS and Rajmane BV (1990). Comparative study of different litter materials for poultry. Poultry Adviser, 13: 21-26. 